\title{
ARBY SAMAH : MAESTRO SENI PATUNG ABSTRAK DI INDONESIA
}

\author{
Harissman $^{1 *}$, Elvis ${ }^{2 *}$, Rica Rian $^{3 *}$ \\ Program Studi Desain Komunikasi Visual ${ }^{1 *}$, Program Studi Seni Murni ${ }^{2 *}$, Program Studi Seni Murni ${ }^{3^{*}}$ \\ Fakultas Seni Rupa dan Desain \\ Institut Seni Indonesia Padangpanjang \\ Jl. Bahder Johan, Guguak Malintang, Padangpanjang, Kota Padangpanjang, 27126. \\ Sumatera Barat. Indonesia \\ Email: harismanomar@gmail.com
}

\begin{abstract}
Abstrak
Penelitian ini membahas tentang penelusuran Arby Samah yang dikenal sebagai pelopor seni patung abstrak di Indonesia, serta mengungkap alasan Arby Samah memilih berkarya patung. Tujuan penelitian ini adalah untuk mengetahui sosok Arby Samah sebagai perintis seni patung abstrak di Indonesia, dan sangat berjasa dalam perkembangan seni patung di Indonesia serta Sumatera Barat khususnya. Kajian teori menggunakan seleksi dan fokus gejala berdasarkan jiwa zaman, menitikberatkan pada perspektif historis mempunyai dua dimensi: aspek masa kini, dan Aspek masa lampau. Metode yang digunakan dalam penelitian ini adalah kualitatif dengan pendekatan deskriptif analisis. Adapun teknik pengumpulan data dilakukan melalui teknik observasi lapangan dan wawancara, pengambilan dokumen yang terkait. Hasil penelitian menunjukkan bahwa Arby Samah berkarya seni patung abstrak dilatarbelakangi oleh faktor: 1) Budaya di Sumatera Barat yang membuat seni patung sulit berkembang. 2) Adat di Sumatera Barat yang mengikat setiap ruang gerak masyarakatnya. 3) Masyarakat di Sumatera Barat mayoritas memeluk Islam yang sangat mengikat dengan hadis dan Al-quran yang melarang membuat patung dalam wujud realis.
\end{abstract}

Kata Kunci: arby samah, patung abstrak, budaya.

\begin{abstract}
This research discussed about a person namely as Arby Samah that has known as a pioneer of art sculpture in Indonesia, it was also to reveal the reason of Arby Samah why choosing sculpture as his work of art. The aim of the research was too see the figure of Arby Samah as a pioneer of art sculpture in Indonesia, and also his contribution to the growth of art sculpture in indonesia especially in west sumatera province. Theory of the research used the selection and observation of the nature symptom. This research focused to the historic perspective that consist of two dimensions, present aspect and past aspect. The method that used in this research was qualitative with descriptive analysis approach. The technique that used in collecting data were field observation, interview and taking the related documents. The result showed that when in producing abstract art sculpture, Arby Samah was influenced by factors: 1) West Sumatera culture that made art sculpture difficult to growth. 2) the tight tradition or the custom of West sumatera, it limited the people to create art sculpture. 3) Islam is the majority religion of the people in west sumatera were in Al Qur'an and Al Hadist has stated that creating sculpture in realist form was prohibited.
\end{abstract}

Keywords: arby samah, abstract sculpture, culture.

\section{PENDAHULUAN}

Dalam perkembangan seni patung di Indonesia Arby Samah merupakan pelopor seni patung abstrak di Indonesia, hal tersebut dibuktikan sewaktu menjadi mahasiswa ASRI Yogyakarta pada tahun 1957, seperti yang dikemukakan oleh Hadi (1996:12) dalam katalog pameran dalam rangka pembukaan Galeri Arby Samah; "sewaktu berkiprah di Yogyakarta sekitar 40 tahun yang lalu, Arby Samah telah menempatkan diri melalui karya-karya patungnya sebagai salah seorang pelopor seni patung modern Indonesia”. Ditambahkan juga oleh Holt dalam bukunya Art In Indonesia, (1967: 226) bahwa: "Di antara mahasiswa-mahasiswa yang lain adalah Arby Samah, yang bergerak ke arah bentuk-bentuk semi-abstrak yang pada waktu itu benar-benar tidak biasa di ASRI Yogyakarta. Ia mencoba bereksperimen di tahun 1955 dengan bentukbentuk tiga dimensi, memahat batu andesit dan mengolah bentuk-bentuk elementer yang geometris dan organik. Karya Arby merupakan tolak ukur dari perkembangan seni patung di Indonesia pada masa itu 


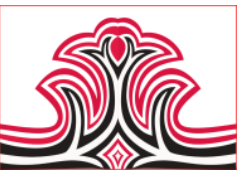

dan merupakan suatu gejala kreatif yang sangat mengesankan".

Dalam proses pencapaian sebagai perintis seni patung abstrak banyak usaha yang dilakukan seperti kotemplasi, eksperimen dan kerja keras. Dalam perenungan, Arby berusaha memikirkan apa yang bisa diperbuat namun tidak melanggar norma-norma atau adat istiadat di kampung halamannya Sumatera Barat. Dalam bereksperimen Arby berusaha melakukan pengolahan bentuk yang bisa mewakilkan identitas dirinya dan usaha mematung yang dilakukannya tidak menyerupai manusia maupun mahluk hidup, sebagaimana prinsip nilai dimana dia hidup dan dibesarkan di tengah-tengah masyarakat mayoritas pemeluk Islam.

Mencermati uraian di atas, predikat yang disandang Arby Samah sebagai pelopor seni patung abstrak di Indonesia merupakan capaian yang tidak semua orang mudah meraihnya, hal itu membutuhkan usaha dan kerja keras. Namun dalam kenyataanya Arby Samah tidak memandang itu suatu yang istimewa atau penghargaan dalam mencapai kesuksesan dalam karirnya sebagai seorang pematung. Penelitian ini akan mengungkap seperti apa perenungan yang dilakukan Arby dalam proses berkarya patung. Selain itu penelitian ini juga akan menelusuri bagaimana bentuk eksperimen yang dilakukan Arby dalam berkarya patung, dan seperti apa kerja keras yang dilakukan Arby dalam membuat karya patung abstrak. Penelitian ini juga mengungkap faktor apa saja yang mempengaruhi Arby Samah dalam berkarya patung sehingga Arby Samah membuat karya yang berbeda dari teman-teman seangkatannya di ASRI Yogyakarta, yakni kreasi dan inspirasinya yang menjadi mengarah kepada patung abstrak.

\section{KAJIAN TEORI}

Bahasan mengenai Arby Samah sebagai pelopor Seni Patung abstrak di Indonesia diperlukan suatu kajian teori sebagai referensi ilmiah yang dapat memperkuat setiap bentuk penelitian. Hal ini juga dimaksudkan untuk menjawab serangkaian pertanyaan penelitian seperti yang telah dirumuskan secara terstruktur. Tujuannya adalah tidak terjadinya bias pembahasan yang sudah dan sedang dilakukan.

Penelitian ini menitik beratkan pada hal yang bersifat uraian sejarah. Fakta dan data yang diperoleh bisa diklasifikasikan sebagai fakta sejarah, dan senada dengan yang diungkapkan oleh Kartodirdjo (1993:4142) bahwa, gambaran masa lampau ditentukan oleh
Gorga : Jurnal Seni Rupa

Volume 08 Nomor 02 Juli-Desember 2019 p-ISSN: 2301-5942 | e-ISSN: 2580-2380

pandangan masa kini. Pandangan masa kini mengarahkan seleksi dan penyorotan gejala berdasarkan jiwa zaman, jadi perspektif historis mempunyai dua dimensi: 1). Aspek masa kini, dan 2). Aspek masa lampau. Dan ditambahkan juga oleh Kartodirdjo (1993: 154) bahwa aspek historis meliputi: a). mentifact, b). socifact, dan c). artifact, (1993: 154. Ketiga fakta tersebut selanjutnya akan dijadikan sebagai penuntun rumusan pendekatan sejarah. teori ini akan digunakan sebagai penuntun permasalahan penelitian.

Becker, (1984: 229) menyatakan bahwa: seniman sepenuhnya mampu menghasilkan karya seni resmi, seniman seperti itu akan sepenuhnya terintegrasi ke dalam dunia seni yang ada, Seniman seperti itu disebut profesional terintegrasi. Profesional terintegrasi memiliki kemampuan teknis, keahlian sosial, dan alat konseptual yang diperlukan untuk memudahkan dalam menciptakan seni. teori ini digunakan untuk menjawab tentang aktivitas kesenimanan Arby Samah.

Selanjutnya, dalam bahasan yang lain juga dipinjam pemikiran Zolberg (1990:165) yang mengemukakan bahwa: seni merupakan konstruk sosial yang muncul dari proses-proses negosiasi bukan entitas-entitas (wujud) tetap, untuk memahami perubahan seni penting kiranya untuk mempertimbangkan, bukan hanya kekuatan-kekuatan yang menyebabkan perubahan itu, tetapi juga hambatan-hambatan untuk perubahan itu. teori ini digunakan untuk menjawab kendala Arby Samah menjalani proses kreatifnya.

\section{METODE PENELITIAN}

Penelitian ini lebih berfokus pada penjelajahan tentang Arby Samah sebagai salah seorang pematung abstrak di Indonesia dengan melakukan pengumpulan data di lapangan dengan observasi langsung dan mewawancarai dengan nara sumber yang terkait dengan subjek penelitian. Pengumpulan data meliputi penelusuran karya patung yang dibuat oleh Arby Samah baik yang masih menjadi koleksi keluarga maupun penelusuran karya lain yang ada melalui katalogus.

Pengumpulan data dengan pendekatan kualitatif dilakukan dengan menetapkan populasi dan sampel untuk memudahkan dalam upaya mencari simpulan yang valid dan reliable. Dalam upaya menentukan populasi dan pengambilan sampel, maka dikumpulkan semaksimal mungkin karya patung abstrak Arby Samah pada awal perintisannya meskipun dalam bentuk foto atau foto reproduksi. Beberapa nara 
sumber juga ditentukan untuk dimintai keterangan mengenai Arby Samah, pemilihan tersebut ditentukan berdasarkan kedekatan dan keterlibatan mereka dalam mengenal Arby Samah. Untuk pengambilan sampel yang dilakukan secara acak, hal itu ditujukan terhadap karya patung Arby Samah yang telah diklasifikasikan populasinya sesuai kriteria tampilan visual karya tersebut, dari masa perintisan sampai pada sketsa yang dibuat Arby pada tahun 1950-an.

Teknik pengumpulan data dilakukan melalui observasi pada karya, studi kepustakaan, studi dokumen, dan studi lapangan. Data yang dibutuhkan dalam penelitian ini dikumpulkan melalui: Metode Kepustakaan, baik data primer maupun data sekunder (untuk melengkapi atau memperkuat data primer) ditelusuri dengan metode kepustakaan, yaitu pelacakan sumber melalui buku-buku, arsip, dokumen, koran, majalah, manuskrip, teks-teks sastra, katalog, brosur, dan sejenisnya yang relevan dengan permasalahan yang dikaji. Metode Observasi, dilakukan langsung ke tempat kediaman Arby Samah dan keluarganya. Data yang diperoleh dimanfaatkan untuk membahas permasalahan yang berkaitan dengan aktivitas berkarya Arby Samah. Alat bantu yang diperlukan berupa kamera video /Hp atau kamera fotografi. Metode Wawancara, dilakukan secara langsung kepada keluarga Arby Samah (istri anak, dan menantu), teman dekat yang sezaman, mantan muridmuridnya, pengamat seni, tokoh masyarakat di sekitar tempat tinggalnya, sebagai informan dalam upaya menghimpun data yang benar.

Penganalisaan data diproses meliputi berbagai tahapan. Pertama indentifikasi data, apakah data yang terkumpulkan dapat memberikan informasi untuk kepentingan penelitian. kedua, klasifikasi data yaitu memilih atau mengelompokkan data penelitian yang telah diidentifikasi sesuai dengan jenis dan sifat data.Tahap ketiga adalah seleksi data, menyeleksi data yang ada mana yang dibutuhkan dan data mana yang tidak mendukung aspek dari tujuan penelitian. Tahapan keempat dilakukan analisis data untuk memberi penguatan terhadap bahasan yang harus diverifikasi

\section{HASIL DAN PEMBAHASAN}

\section{Hasil}

Arby Samah Dt. Majo Indo kelahiran 1 April 1933 di daerah Pandai Sikek Sumatera Barat merupakan suatu daerah di Minangkabau yang sebahagian besar masyarakatnya terkenal sebagai orang-orang yang pandai mengukir dan menenun. Menjadi perupa sudah
Gorga : Jurnal Seni Rupa

Volume 08 Nomor 02 Juli-Desember 2019 p-ISSN: 2301-5942 | e-ISSN: 2580-2380

mengalir dalam darahnya sejak kecil apalagi Arby dibesarkan dalam keluarga yang juga bergelut dalam dunia seni, dan untuk mengasah kemampuannya pada tahun 1948 Arby disekolahkan orang tuannya di Kayutanam tepatnya di INS (Indonesich Nederlandsche Scool).

Setelah menamatkan pendidikan di INS dan berkat rekomendasi dari A.A. Navis dan Ramudin, Arby melanjutkan pendidikan di Akademi Seni Rupa Indonesia (ASRI) Yogyakarta pada tahun 1953. Direkomendasikannya Arby Samah untuk menempuh pendidikan di ASRI ini merupakan program pemerintah Provinsi Sumatera Barat yang bertujuan supaya setelah mereka menamatkan pendidikan bisa pengembangkan ilmu yang didapat di kampung halamannya di Sumatera Barat.

Melanjutkan pendidikan ke Akademi Seni Rupa Indonesia di Yogyakarta pada tahun 1953 merupakan satu-satunya jalan bagi Arby untuk memperdalam ilmu tentang seni patung, namun warisan pendidikan Eropa masa itu yang lebih mengutamakan bentukbentuk patung realis telah "memaksa" Arby untuk mengikutinya dengan arti kata Arby Samah di ASRI mulanya menganggap, bahwa seni patung adalah seni yang meniru alam yang figuratif. Tapi karena kebiasaan tradisi dan akar budaya Minangkabau tidak mengajarkan kepada bentuk-bentuk yang realis, Arby mendapat kesulitan pada mulanya, namun berkat etos kerja yang tinggi, Arby menjadi seorang realis yang disegani.

Arby Samah di antara teman-temannya dikenal sebagai mahasiswa yang mahir membuat karya patung lewat tanah liat. Seperti dikutip dalam tulisan Yusrizal (25 Mei 2007) di harian Singgalang, "73 Tahun Arby Samah Tak Pindah Ke Lain Hati”, disebutkan bahwa: ketika Arby Samah mengerjakan patung potret Kustiyah (teman sewaktu mudanya di Yogyakarta). Ketika potret Kustiyah tersebut selesai maka berkunjunglah teman-teman dan dosen Arby ke studionya. Begitu melihat patung Kustiyah terkejutlah semuanya "Kagum dan terharu" Karena patung tersebut persis sekali dengan karakter Kustiyah pokoknya bentuk dan karakternya sempurna sekali”.

\section{Pembahasan}

Awal mula kemunculan karya abstrak Arby Samah yang berjudul "Ibu dan Anak" yang dibuat pada media batu tahun 1955, pada waktu itu membuat karya dengan bahan batu menjadi tren bagi mahasiswa patung di ASRI, begitu karya Arby dilihat oleh teman- 


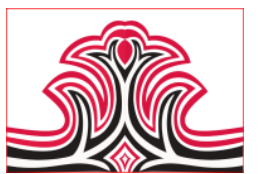

temannya banyak yang kagum dan ada juga yang membenci termasuk Presiden Soekarno pada tahun 1957 ke Yogyakarta Seperti tulisan Darman Moenir dalam harian Singgalang tanggal 6 Agustus 1998 yang berbunyi: "Arby Samah menghasilkan karya bukan asal jadi atau jadi-jadian.

Walapun karya Arby ditolak presiden Soekarno dan Soeharto namun Claire Holt dalam buku "Melacak Jejak Perkembangan Seni Indonesia” (2000:341) menuliskan bahwa Arby Samah masuk dalam sejarah perkembangan seni patung di Indonesia yang mana tulisan tersebut berbunyi "Di antara mahasiswamahasiswa patung yang lain adalah Arby Samah, yang bergerak ke arah yang sangat berbeda.

Perpindahan Arby Samah dari patung realis ke patung abstrak bagi kalangan pematung masa itu dianggap sebagai suatu yang "aneh" akan tetapi pada hakekatnya, saat perpindahan itulah momentum pada dirinya untuk "kembali pulang" kepada akar budayanya, kembali kepada bentuk-bentuk ornamentik, simbolik dan dinamik yang telah disediakan budayanya. Arby membuat patungnya dengan tatahan kasar, ekspresif dan bahkan "fauvist" (keliaran) sehingga emosi, ekspresinya dapat tersalur dengan baik. Ada yang menarik dan spesifik dari patung-patung karya Arby Samah yang berjudul "Gadis Desa", "Ibu dan Anak", "Gadis Kota", "Gadis dan Anak", "Sejoli", "Gadis Kupang", "Gadis di Bukit Karang", "Tetesan Bunda", "Dua Gadis" dan "Mulanya Terjadi". Bisa ditebak betapa kaum perempuan mendapat tempat dalam karya-karyanya, menurut Arby perannya perempuan sangat luar biasa dalam kehidupan pemahaman terhadap perempuan.

Jika rujukan budaya yang dipakai untuk memahami patung-patung Arby Samah dapat dikatakan sebagai "perpanjangan" dari ukiran-ukiran tradisi Minang. Andil Arby Samah terbesar dalam memperpanjang itu adalah; dia telah memberikan "nafas" baru pada seni ukir. Akan tetapi pihak "luar" seperti pengamat seni rupa, atau pematung lainnya hanya melihat seni patung sebatas "benda" atau "sosok", menganggap Arby Samah sebagai pematung abstrak pertama di Indonesia, dan itu sejalan bagi kreativitasnya karena berbalik kepada akar budayanya yang non-figuratif atau abstrak.
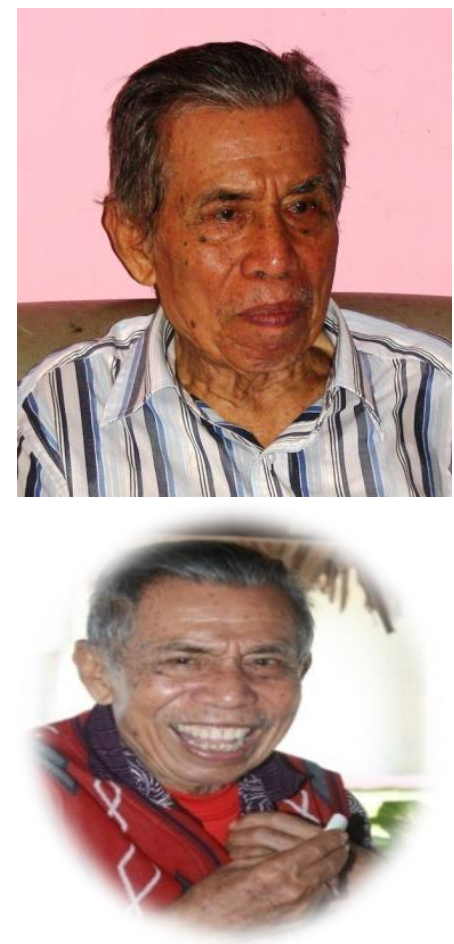

Gambar 1. Potret diri Arby Samah

(Sumber: Rica Rian Dokumentasi dari Keluarga Arby Samah, 2018)

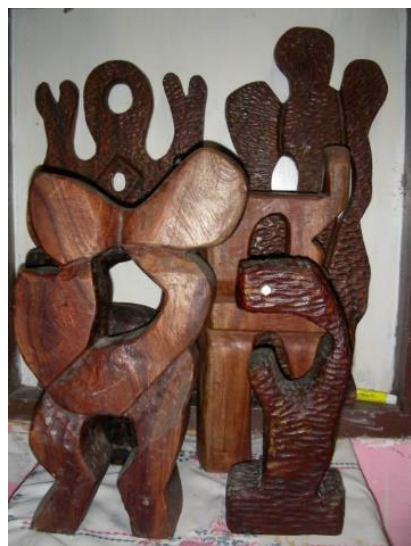

Gambar 2. Beberapa Karya Patung Arby Samah (Sumber: Rica Rian Patung Koleksi Keluarga Arby Samah Tahun 2012, 2018)

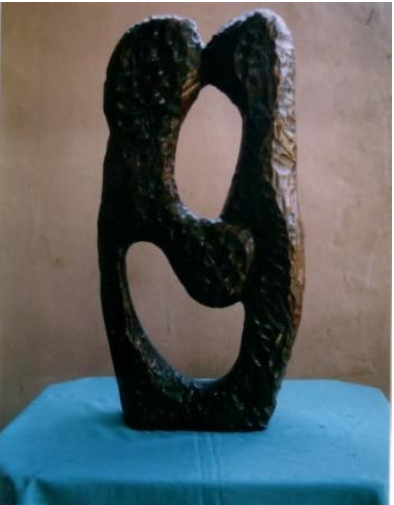

Gambar 3. "Gadis Desa" Karya Arby Samah

(Sumber: Rica Rian Patung Koleksi Keluarga Arby Samah Tahun 2012, 2018) 


\section{Faktor Yang Mempengaruhi Arby Samah Berkarya.}

\section{1). Faktor Masyarakat}

Kehadiran karya-karya patung Arby tidak bisa lepas dari pengaruh lingkungan masyarakat sebagai penikmat. Dalam masyarakat sendiri ditanamkan nilainilai keagamaan sejak dini sehingga ajaran Islam mengalir kuat dalam dirinya. Masih banyak di antara masyarakat menganggap karya patung sebagai perwujudan berhala, seperti yang dijelaskan oleh Yusuf, (2004:167-168), Gambar-gambar dan patungpatung adalah benda-benda paling populer di kalangan penganut paham keberhalaan.

Sesungguhnya seorang Arby Samah sebagai pematung atau seniman dipengaruhi oleh masyarakatnya di mana dia tumbuh dan berkembang, diantaranya:

Budaya Minangkabau tidak memperkenalkan bentukbentuk realistik dalam seni rupa (akibat pengaruh ajaran Islam dari suatu mazhab) terutama pada seni patung. Pada hakekatnya seni rupa di Minangkabau adalah seni rupa terpakai (applied art).

Semua benda-benda itu dihiasi dengan berbagai ragam hiasan yang ornamentik, symbolik dan dinamik. Ragam hias yang ornamentik itu merupakan sesuatu bentuk dari alam yang sudah distilir atau dideformasi menjadi motif-motif hiasan atau ukiran dalam kemasan dekoratif.

Tinjauan terhadap faktor masyarakat, adalah sangat berperan sebagai pendukung dan penolakan terhadap karya-karya patung Arby seperti yang diungkapkan oleh Putra, ed, (2007:47) bahwa, "Alam Takambang Jadi Guru” merupakan suatu metode untuk melambangkan aturan bermasyarakat yang sejalan dengan hukum alam dan kehidupan.

\section{2). Faktor Agama}

Dalam ajaran Islam melarang umatnya membuat patung, hal itu disebabkan adanya larangan Al-qulan dan hadis. Kesenian Islam tidak harus berbicara tentang Islam. Ia tidak harus berupa nasihat langsung, atau anjuran berbuat kebajikan, bukan juga penampilan abstrak tentang akidah. Seni yang Islami adalah seni yang dapat menggambarkan wujud dengan bahasa yang indah serta sesuai dengan cetusan fitrah manusia.

Adanya hadis yang menyatakan larangan seniman muslim membuat patung, sehingga ruang gerak aktivitas seniman menjadi sempit dan terbatas. Di
Gorga : Jurnal Seni Rupa

Volume 08 Nomor 02 Juli-Desember 2019 p-ISSN: 2301-5942 | e-ISSN: 2580-2380

bawah ini disebutkan dua hadis yang menerangkan larangan tersebut, seperti yang dinyatakan Jabrohim dan Berlian.ed (1995:218),Pertama: Hadis riwayat al Bukhari dan Muslim dari Aisyah r.a mengatakan bahwa orang yang paling berat azab di hari qiamat ialah mereka yang menyamakan ciptaannya dengan ciptaan Allah. Kedua: Hadis serupa dengan lafas lain dari riwayat al Bukhari dan Muslim menyatakan bahwa: pembuat gambar atau patung itu akan disiksa dihari qiamat. Mereka diperintahkan untuk menghidupkan (memberi nyawa) apa yang telah mereka buat.

\section{3). Faktor Adat}

Falsafah hidup yang menjadi acuan adat dalam kehidupan bermasyarakat yang berlandaskan adat basandi syara', syara' basandi kitabullah. Syara' mandaki adat manurun. Syara' mangato, adat mamakai. Maksudnya adat bersendikan syariat Islam, syariat Islam bersendikan Al-Quran. Aturan hukum serta norma-norma adat dalam kehidupan bermasyarakat di Sumatera Barat berdasarkan syariat Islam.

Dalam masyarakat Minangkabau adat merupakan pusako (pusaka), dalam artian bahwa adat akan selalu ada sampai kapanpun, sekalipun manusia sebagai pendukungnya meninggal tetapi adat akan selalu tumbuh dan berkembang oleh generasi selanjutnya.

\section{KESIMPULA DAN SARAN \\ 1.Kesimpulan}

Pada tahun 1957 Arby Samah mendapatkan predikat sebagai pelopor seni patung abstrak di Indonesia, capaian tersebut tidak lepas dari faktor budaya di Sumatera Barat yang mempengaruhinya, yakni: Faktor kehidupan masyarakat di Minangkabau yang menanamkan nilai-nilai keagamaan sejak dini sehingga ajaran Islam mengalir kuat dalam dirinya. Faktor agama: alam ajaran Islam melarang umatnya membuat patung, hal itu disebabkan adanya larangan Al-qulan dan hadis. Faktor adat: yang merupakan suatu paham atau ajaran yang tidak mendewakan benda atau materi karena orang Minangkabau mengagungkan sesuatu yang gaib atau tuhan Yang Maha Esa. Ketiga faktor itulah yang mempengaruhi Arby berkarya patung hingga sampai pada bentuk abstrak dan dikenal di Indonesia sebagai pematung abstrak.

\section{Saran}

Menelisik perjalanan Arby Samah sebagai pematung abstrak, kiranya sangat diperlukan lagi penjelajahan 


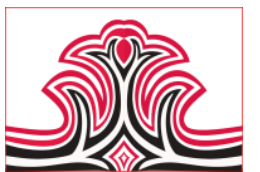

dinamika kehidupan kesenimanan Arby Samah untuk dicermati secara lebih jauh. Tentu harapan ke depan bagi peneliti dan menggiat seni bisa member pembelajaran atas konsep kreatif serta eksekusi benda kreasi dalam bentuk-bentuk patung Arby Samah yang non figuratif.

\section{DAFTAR RUJUKAN}

Becker, S, Howard. (1984). Art Worlds, University of California Press Berkeley and Los Angeles, London: Calofornia University Press.

Holt, Claire. (1967). Art in Indonesia: Continuities and Change atau Melacak Jejak Perkembangan Seni di Indonesia, diterjemahkan oleh R. M Soedarsono. Bandung: Arti Line.

Jabrohim dan Berlian, Saudi. Ed. (1995). Islam dan Kesenian. Jakarta: Majelis Kebudayaan.

Kartodirdjo, Sartono. (1993), Pendekatan Ilmu Sosial Dalam Metodologi Sejarah. Jakarta: Gramedia Pustaka Utama.

Putra, Yerri S. Ed. (2007). Minangkabau di Persimpangan Generasi. Pusat Studi Humaniora dan Fakultas Sastra. Universitas Andalas. Padang.

Qardhawi, Yusuf. (2004), Islam Bicara Seni. Solo: Era Intermedia.

Read, Herbert. (1969), The Art of Scupture. Washington D.C: Princeton University Press.

Salad, Hamdy. (2000). Agama Seni Refleksi Teologis dalam Ruang Estetis. Yogyakarta: Yayasan Semesta.

Zolberg,L,Vera. (1990). Contracting A Sosiology of the Art. New York: Cambridge University Press.

\section{Katalog dan Koran}

Hadi, Wisran. (30 September 1996), Arby Samah Membangkit Batang Tarandam Untuk di Patungkan Kembali, Haluan.

Yusrizal (25 Mei 2007) “73 Tahun Arby Samah Tak

Pindah Ke Lain Hati" di Harian

Singgalang. 